\title{
UNA APLICACIÓN DEL MATCHED-GUISE PARA EL ESTUDIO DE ACTITUDES EN LENGUAS EN CONTACTO DE LA PENÍNSULA DE YUCATÁN: MAYA, ESPAÑOL E INGLÉS EN CONTEXTOS URBANOS \\ AN APPLICATION OF THE MATCHED-GUISE TECHNIQUE FOR THE STUDY OF ATTITUDES IN THE CONTACT LANGUAGES OF THE YUCATAN PENINSULA: MAYAN, SPANISH AND ENGLISH IN URBAN CONTEXTS
}

\author{
Eyder Gabriel Sima Lozano \\ Universidad Autónoma de Baja California, Campus Ensenada \\ Edith HeRnÁndez MÉndeZ \\ Universidad de Quintana Roo, Campus Chetumal
}

\begin{abstract}
Resumen: Dentro del panorama general de estudios sobre actitudes linguíísticas en la península de Yucatán, se han efectuado diversos trabajos atendiendo principalmente a la lengua maya, pero no se ha hecho alguno en relación con el español y el inglés, aplicando la técnica del matched-guise. En este estudio, usando dicho instrumento, se estudian las actitudes hacia el maya, español e inglés en tres contextos urbanos de la región, con la expectativa de que los resultados sean útiles en ámbitos como la política y la planificación linguíística, así como la educación.
\end{abstract}

Palabras clave: actitudes linguiísticas, matched-guise, maya, español, inglés.

Abstract: Previous studies of language attitudes in the Yucatan peninsula have addressed mainly the Mayan language, but none has been conducted that consider Spanish or English, nor using the matched-guise technique. Consequently, this instrument was used in the present article to study the attitudes towards Mayan, Spanish, and English in three urban contexts in the region. The findings are expected to be useful in areas such as language policy and planning, as well as in education.

KeYwords: Linguistic attitudes, matched-guise, Maya, Spanish, English.

RECEPCIÓN: 28 de enero de 2015.

ACEPTACIÓN: $1^{\circ}$ de mayo de 2015. 



\title{
UNA APLICACIÓN DEL MATCHED-GUISE PARA EL ESTUDIO DE ACTITUDES \\ EN LENGUAS EN CONTACTO \\ DE LA PENÍNSULA DE YUCATÁN: MAYA, ESPAÑOL E INGLÉS EN CONTEXTOS URBANOS
}

\author{
Eyder Gabriel Sima Lozano \\ Universidad Autónoma de Baja California, Campus Ensenada \\ Edith HeRnÁndez MÉndez \\ Universidad de Quintana Roo, Campus Chetumal
}

\section{Introducción}

Desde la Sociolinguiística, el estudio de las actitudes linguiísticas ha cobrado importancia para identificar los procesos de vitalidad, mantenimiento, desplazamiento, muerte de lenguas, lenguas en contacto y lenguas en conflicto (Barragán Trejo, 2006, 2009; Fishman, 1974, 1979, 1991; Haugen, 1978; Lastra, 1992; Lavandera, 1978; Silva-Corvalán, 1986; Rico Lemus, 2010; Terborg, 2006; Terborg y Velázquez Vilchis, 2005, 2008; Terborg y García Landa, 2011a, 2011b; Trujillo Tamez, 2012). Dichos estudios constituyen un paradigma para la preservación de los idiomas, en particular los indígenas, que enfrentan un destino incierto (LeónPortilla, 2004; Nettle y Romaine, 2000).

Para preservar la diversidad linguiística se deben identificar las actitudes de los hablantes hacia sus lenguas y otras con las que están en contacto, pues ello puede conllevar a la creación de políticas del lenguaje integracionistas que tomen en cuenta no sólo una lengua, ya que las situaciones de bilingüismo o trilingüismo exigen una planeación incluyente para todas, especialmente si forman parte de un contexto de lenguas en contacto.

Por lo anterior, es objetivo de este trabajo ${ }^{1}$ analizar actitudes hacia las lenguas maya, español e inglés en tres contextos urbanos de la península de Yucatán, recurriendo a la técnica conocida como matched-guise. ${ }^{2}$

\footnotetext{
${ }^{1}$ Este trabajo es resultado del proyecto de investigación: PAPIT IN404313 "Situaciones y prácticas bilingües que contribuyen al mantenimiento-desplazamiento de lenguas. Análisis del conocimiento y de la 'máxima facilidad compartida' como sistemas complejos", financiado por la UNAM.

2 O "par oculto", como se ha traducido por algunos al español.
} 
Las tres ciudades que elegimos para nuestro estudio (Cancún, Mérida y Chetumal) representan polos de fuerte presencia de monolingüismo en español, bilingüismo en maya y español, bilingüismo en español e inglés, bilingüismo en inglés y maya y trilingüismo, ya que tanto Cancún y Mérida son imanes de atracción migratoria para los bilingües de maya y español, así como para personas que usan el inglés como segunda lengua dadas las actividades laborales turísticas, mientras que en Chetumal, zona fronteriza con Belice, si bien el turismo no es una actividad de fuerte presencia, existen hablantes de maya y personas provenientes del vecino país anglófono, por lo que ambos idiomas conviven con el español.

En México son escasos los estudios de actitudes de lenguas en contacto que han usado la técnica del matched-guise; los pocos que existen han atendido la relación de un idioma indígena con el español, como son el caso de Terborg acerca del otomí (2004) y Castillo Hernández con el náhuatl (2007), que analizan contextos rurales, mientras que Terborg y Velázquez Vilchis se enfocan en uno de tipo urbano con el otomí (2008).

Respecto a la península de Yucatán en su conjunto, los estudios de actitudes que han usado la técnica del matched-guise son también exiguos. ${ }^{3}$ Si bien Pfeiler (1993), Durán Caballero y Sauma Castillo (2003) y Sima Lozano (2012) han aplicado dicho instrumento para estudiar el maya yucateco y el español, se han limitado al estado de Yucatán. El primero, en un contexto rural, y los dos últimos en el ámbito urbano de la ciudad de Mérida, pero ningún trabajo ha tomado en consideración el inglés en su relación con las actitudes hacia el maya y el español, ni tampoco se ha comparado un contexto interestatal como aquí lo hacemos al analizar tres ciudades de dos estados peninsulares mexicanos, Yucatán y Quintana Roo ${ }^{4}$ (ver anexo C).

Así, las preguntas que guían esta investigación son ¿cuáles son las actitudes de tres sectores de población urbana de la península de Yucatán hacia las lenguas maya, español e inglés? y ¿qué ventajas o desventajas tiene el instrumento del matched-guise en su aplicación al estudio de las actitudes linguíísticas en la región?

El trabajo espera contribuir a los estudios de mantenimiento y desplazamiento de lenguas indígenas, pero también incorporar a estas perspectivas lo que acontece con lenguas como el español y el inglés, siendo esta última usada en una situación predominantemente de bilingüismo por elección. Asimismo, los que desarrollan políticas y planificación del lenguaje pueden usar esta investigación como un antecedente para futuros trabajos en los que se integren las tres lenguas en contacto, pues es un hecho que la convivencia entre ellas ha generado una visión particular en los habitantes de la zona.

\footnotetext{
${ }^{3}$ Vale la pena mencionar que en el ámbito nacional y regional de la península de Yucatán, se han llevado a cabo estudios de actitudes usando otras técnicas, como la entrevista y los cuestionarios (Castillo Hernández, 2007; Álvarez Murillo, 2008; Jiménez Peraza, 1982; Sánchez Arroba, 2009; Sima Lozano, 2011; Sima Lozano, 2012; Sima Lozano, Perales Escudero y Be Ramírez, 2014).

${ }^{4}$ Faltaría incorporar alguna ciudad del estado de Campeche para que el estudio pueda representar de manera óptima la región peninsular. Dejamos pendiente esta tarea para otro trabajo con las mismas perspectivas teórica y metodológica.
} 


\section{Marco teórico}

Perspectivas conceptuales de actitudes lingüísticas

La definición de actitud lingüística que guía este trabajo está basada en Castillo Hernández, quien la consigna como "una manifestación valorativa que proyecta la percepción que se tiene hacia las personas de grupos diferentes que hablan determinada lengua” (2007: 26). Este constructo permite conocer el estado de salud de un idioma o de las lenguas que están en contacto; ejemplo de esto último sucede en la península de Yucatán, donde la lengua maya convergió en una situación histórica y de adstrato con el español, lo que originó el español yucateco. Actualmente el maya también ha entrado en contacto con el inglés, pues los proyectos turísticos de la región, las ofertas laborales y la enseñanza de lenguas extranjeras han generado una fuerte propaganda hacia el idioma anglosajón y un constante contacto con angloparlantes.

Se han aplicado diversas técnicas para la realización de estudios de actitudes, pero existen dos posturas de donde se desprenden los procedimientos: la primera concepción es la conductista, la cual sostiene que las actitudes están en las respuestas que las personas manifiestan ante situaciones sociales, por lo que la entrevista y la observación son las técnicas usadas (Blas Arroyo, 1999). La segunda, de tipo mentalista, señala que las actitudes son parte de un proceso interno del individuo, que tiene una disposición mental hacia ciertas condiciones o hechos sociolinguiísticos concretos (Castillo Hernández, 2007). La técnica preferida de esta posición es la que se conoce como matched-guise. ${ }^{5}$

La técnica del matched-guise

La técnica del matched-guise o "par oculto", como la llama en español González Martínez (2008), fue creada por Lambert (1967) en Canadá. Consistió en la presentación de dos grabaciones, una en inglés y otra en francés, a estudiantes bilingüies de secundaria, quienes evaluaron la personalidad de las voces, con el supuesto de que cada una de éstas representaba una persona diferente que hablaba uno de esos idiomas, aunque en realidad era el mismo individuo usando las dos lenguas. Los anglófonos resultaron ser los mejor evaluados.

A partir del diseño de Lambert la técnica ha recibido diversas modificaciones y críticas. Una de las más notables es que los jueces no siempre evalúan la lengua, ya que se tiende a examinar la calidad de la grabación, el tema de la conversación, el tipo de voz o el acento de los participantes, por lo que se sugiere tener

\footnotetext{
${ }^{5}$ Lo anterior no implica que un estudio de actitudes se limite a una postura, pues Durán Caballero y Sauma Castillo (2003), Terborg (2004), Castillo Hernández (2007) y Sima Lozano (2012) usan al mismo tiempo entrevistas, cuestionarios y la técnica del matched-guise. Cada estudio elige delimitar su trabajo a una u otra técnica, o a una combinación de varias de ellas.
} 
cuidado en el diseño de la prueba a fin de que el evaluador no se distraiga con esos aspectos.

Entre las variaciones que presenta la técnica existe una que consiste en la presentación de cuatro grabaciones en las que se usan dos lenguas. Las cuatro grabaciones se mezclan; en un par de ellas habla el mismo sujeto, en las otras dos hablan personas diferentes y se consideran como distractores, por lo que el juez supone que todas las personas son distintas.

Los componentes de las actitudes lingüísticas

Por último, cabe mencionar que como parte de la teoría de las actitudes, en particular del enfoque mentalista, existen tres componentes diferenciados que son evaluados indistintamente por los hablantes, según la orientación de los instrumentos para medir actitudes linguí́sticas. El primero es el cognitivo, que se refiere a los saberes y el conocimiento de la lengua; el segundo es el afectivo, que analiza los valores y evaluaciones hacia el idioma, y el tercero, el conductual, que trata la reacción y conducta hacia un idioma (Baker, 1992).

Entre los antecedentes que han usado la técnica del matched-guise en la región peninsular es notorio el enfoque de evaluación hacia uno de los componentes de las actitudes. Tanto Pfeiler (1993) como Durán Caballero y Sauma Castillo (2003) se enfocan en el componente afectivo, mientras que Sima Lozano (2012) en el conductual.

\section{Las comunidades de habla}

Como es sabido, la península de Yucatán está conformada por tres entidades políticas: Campeche, Quintana Roo y Yucatán. La inmigración en la península ha sido muy intensa en las últimas décadas, a expensas tanto de migrantes interestatales de la región como provenientes de otros estados. Según el INEGI, en 2010 llegaron a Quintana Roo 143899 personas, cuya procedencia se distribuía de la siguiente manera: $16 \%$ de Yucatán, $14 \%$ de Tabasco, $12 \%$ de Veracruz, $15 \%$ de Chiapas y $13 \%$ del Distrito Federal. Por su parte, en ese mismo año llegaron a Yucatán 49815 personas: 34\% de ellas de Quintana Roo, 13\% de Campeche, 13\% del Distrito Federal, 9\% de Tabasco y 6\% de Veracruz (2010a, 2010b). Quintana Roo y Yucatán, por ser enclaves turísticos, se han convertido en polos económicos atractivos tanto para indígenas y no indígenas nacionales, quienes traen consigo sus lenguas y dialectos particulares.

Por otra parte, la inmigración internacional se registra principalmente en Mérida (en el caso de Yucatán) y en Cancún, Playa del Carmen, Tulum y Cozumel (en el de Quintana Roo). En estos lugares es común encontrar, por ejemplo, anuncios en tiendas y menús en restaurantes solamente en inglés; anuncios señalando que se habla esa lengua, o prestadores de servicios que se dirigen a todo el público 
en inglés en primera instancia. Las estancias de los turistas varían de unos días a meses, si bien hay quienes deciden residir en México, ya que estos lugares turísticos son de su preferencia.

En la península, el español convive con la lengua maya desde la época colonial en una situación de bilinguiismo histórico y cultural. En términos estadísticos, la lengua maya yucateca cuenta con 786113 hablantes, siendo la segunda lengua indígena con mayor número de hablantes en México después del náhuatl, según el INEGI (2010c). La población se distribuye en los estados peninsulares del siguiente modo: Yucatán con 537618 mayahablantes, Quintana Roo con 177979 y Campeche con 71852.

Pfeiler señala que en la península de Yucatán el uso del español y el maya varía según las regiones económicas; la pesquera, por ejemplo, es la que tiene menos hablantes del maya. En Campeche, el español predomina sobre el maya en el occidente y sur del estado, mientras que en Quintana Roo se observan tres -regiones con un diferente uso de lenguas: el Caribe, con predominio del español y del inglés; el centro, región linguiística maya más conservadora, y el sur, donde predomina el uso del español. Esta situación, apunta la autora, se debe a "una infraestructura ampliada de las comunidades rurales y (a) una tasa alta de migración relacionada con el turismo y el crecimiento de las ciudades" (1999: 269). Coincide con esto último Sánchez Arroba, quien apunta a la deprimida economía de los pueblos indígenas como causa importante de la emigración y pérdida de la lengua maya en Quintana Roo (2009).

Chetumal, capital de Quintana Roo, y lugar donde se desarrolló el presente estudio, se localiza en el sur-este de la península y del estado. Al sur, y a unos treinta minutos, tiene como vecino al país de Belice (donde el inglés es el idioma oficial, pero se hablan también el español, el inglés criollo, el chino y el hindi, entre otras lenguas); al norte de la ciudad capital, pero en el centro del estado, se localizan ciudades y pueblos que integran la llamada zona maya, donde el maya y el español pueden coexistir, pero se observa el dominio del primero. Más al norte y bordeando el Caribe, se ubican ciudades turísticas como Tulum, Playa del Carmen y Cancún, donde se escucha español e inglés y, en menor medida, maya y diversas lenguas europeas.

En el municipio de Othón P. Blanco — del cual Chetumal es parte- la población mayahablante es de 21859 según el INEGI (2010c). Las actividades principales en Chetumal son la gestión del gobierno, el comercio y la educación. Estudiantes provenientes de Belice y de otras ciudades y pueblos del estado participan día con día en el mosaico cultural de la ciudad. Inmigrantes de diversos estados del país han hecho de Quintana Roo su nuevo hogar, y Chetumal ha sido uno de esos polos de atracción para muchos de ellos. Gente originaria de Yucatán, Ciudad de México, Veracruz, Tabasco y, más recientemente, de Chiapas, ha emigrado a la capital del estado. Por supuesto, inmigrantes del mismo estado también se han integrado a esta ciudad, y, entre ellos, muchos mayahablantes. Si bien, como señala Pfeiler (1999), el español predomina en el sur de Quintana 
Roo, aún en las calles, mercados o en las aulas escolares se observan rasgos de un bilingüismo instrumental (español L1-maya L2 limitado) y, en menor medida, de un bilingüismo consecutivo (maya L1-español L2).

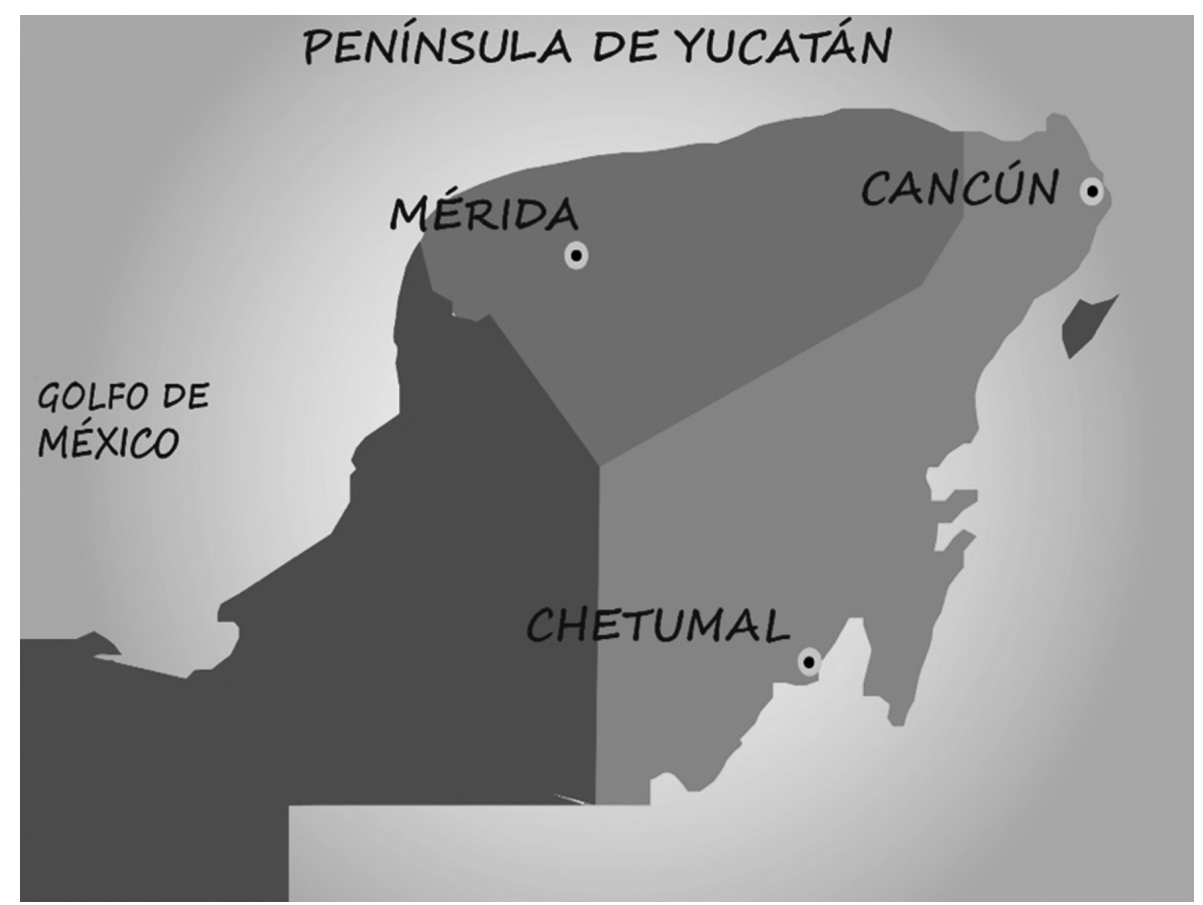

MAPA 1. Península de Yucatán y las ciudades de Mérida, Cancún y Chetumal.

Por su parte, Mérida, capital de Yucatán, se caracteriza por ser la urbe más poblada de la península. Ciudad colonial, fundada en 1542, cuenta con una población estimada en 830732 habitantes, de un total de 1955577 registrados para todo Yucatán (INEGI, 2011a). Caracterizada por tener una alta población de mayas inmigrantes del interior del estado, el INEGI (2011a) reportó que la ciudad (segundo polo de atracción regional para migrantes, después de Cancún) concentra un $10 \%$ de bilingües de maya y español.

Mérida es hoy un gran polo de migración de yucatecos del interior del estado, tanto bilingües de maya-español como monolingües de español, al mismo tiempo que llegan a ella constantemente individuos provenientes de los estados fronterizos y de otros estados del país, atraídos por la tranquilidad y los bienes y servicios que ofrece, entre los que destacan el médico, el educativo y el cultural. El turismo contribuye a que el inglés sea una lengua muy apreciada entre la población y, junto con el maya, constituye entre los habitantes un saber que la gente explica de la siguiente forma: "El que sabe maya e inglés, donde sea se defiende". 
Cancún, la ciudad más poblada del estado de Quintana Roo, es además un polo turístico del Caribe mexicano que fue creado para el desarrollo de la región. Cuenta con una enorme infraestructura, considerada en 145 espacios hoteleros con 30608 habitaciones (INEGI, 2014) y, junto con el corredor de la Riviera Maya a lo largo de la costa norte del estado de Quintana Roo, ha sido un detonador de la economía para la entidad y la región, pues los turistas que llegan a Cancún por lo general acuden al vecino estado de Yucatán para visitar sitios arqueológicos próximos como Chichén Itzá.

A esta ciudad, que tiene aproximadamente 628306 habitantes, según el INEGI (2010d), constantemente llegan migrantes nacionales, entre los que destacan los de origen yucateco, por lo que no es difícil encontrar mayahablantes provenientes de Yucatán (Be Ramírez, en prensa; Fortuny Loret de Mola, 2004) y del centro de Quintana Roo. Los yucatecos ocupan el primer lugar de migración hacia Cancún, debido a la cercanía interestatal entre Quintana Roo y Yucatán. Así, el número de población originaria de Yucatán presente en Cancún se aproxima a las 125000 personas, según el INEGI (2011b).

\section{Método}

Como mencionamos líneas arriba, nuestro estudio se realizó en tres contextos urbanos. Aplicamos la técnica del matched-guise a un grupo de población atendiendo variables sociales como el sexo, la edad y la lengua materna. Presentamos en la tabla 1 la distribución de los participantes correspondientes a cada ciudad.

\begin{tabular}{|c|c|}
\hline Ciudad & Participantes \\
\hline Cancún & 20 \\
\hline Chetumal & 22 \\
\hline Mérida & 21 \\
\hline Total & 63 \\
\hline
\end{tabular}

TABLA 1. Distribución de los participantes por ciudad.

En la tabla 2 se muestran las frecuencias de las tres variables, según la localidad analizada. Para la variable de sexo, se consideraron hombres y mujeres; para la etaria se tomaron en cuenta cuatro grupos (de 18 a 28, de 29 a 39, de 40 a 50 y de 51 años en adelante), y para lengua materna se integraron monolinguies de español, bilingües de maya y español y bilingües de español e inglés en una situación en la que este último es hablado como segunda lengua. ${ }^{6}$

${ }^{6}$ El estudio no incluye a monolingües de maya debido a que es difícil encontrarlos en las zonas urbanas que estudiamos. Consideramos que sería más fácil localizarlos en zonas rurales de la península de Yucatán. También existen los monolingües de inglés, pero si el estudio fuera aplicado a ellos tendríamos que enfocarlo solamente en esa lengua anglosajona; por eso elegimos una muestra de bilingües de inglés y español para contrastar las lenguas en contacto. 


\begin{tabular}{|l|c|c|c|}
\hline \multicolumn{1}{|c|}{ Sexo } & Cancún & Chetumal & Mérida \\
\hline Hombre & $\mathrm{N}$ & $\mathrm{N}$ & $\mathrm{N}$ \\
\hline Mujer & 11 & 11 & 13 \\
\hline \multicolumn{1}{|c|}{ Edad } & & 11 & 8 \\
\hline 1 (18 a 28) & 7 & 8 & 10 \\
\hline 2 (29 a 39) & 3 & 3 & 3 \\
\hline 3 (40 años en adelante) & 2 & 2 & 1 \\
\hline 4 (51 años en adelante) & 10 & 11 & 11 \\
\hline \multicolumn{1}{|c|}{ Idioma } & 10 & 11 & \\
\hline Bilingüismo & & & 7 \\
\hline Monolingüismo & & & \\
\hline
\end{tabular}

TABLA 2. Datos: sexo, edad e idioma de los informantes.

Como podemos observar, los grupos sexo (mujer y hombre) y tipo de hablante (bilingüe y monolinguie) son proporcionados en las tres muestras, pero el grupo etario presenta números reducidos en los subgrupos 3 (40-50 años) y 4 (más de 51). Esto se debió a que muchos informantes de tales grupos no supieron cómo responder la prueba, y se limitaron a expresar valores muy altos o muy bajos para todos los reactivos; datos que no se incluyeron en el análisis, ya que afectan los resultados relacionados con la variable de edad. Si bien otros datos, como el lugar de origen y la actividad a la que se dedican podrían ser de interés para este tipo de estudio, no se incluyeron debido a que no se contaba con una muestra representativa de estos otros factores.

Para el diseño del instrumento, matched-guise, se utilizó un pequeño diálogo de una situación en la calle en el que uno de los hablantes preguntaba por una dirección. El par oculto, que en este caso fue un trío oculto, se realizó por un bilinguie de maya-español y que habla inglés con cierto dominio. Dado que el inglés en México es una lengua extranjera, se consideró que el nivel de este hablante era adecuado para el test. Es decir, ya que los mexicanos que hablan inglés lo hacen como lengua extranjera (sin tanta fluidez ni precisión), el nivel de esta persona era similar en este aspecto. Se incluyeron como distractores otros tres diálogos: uno en maya, uno en inglés y otro en español, grabados por distintas personas (ver anexo A). Todos los bilingüies de maya-español en 
estas grabaciones hablaban una variante dialectal del maya de Quintana Roo, pero fueron los únicos que estaban a nuestro alcance.

La grabación consistió en un diálogo en el que una mujer le pregunta a un hombre ${ }^{7}$ cómo llegar a la Plaza de Las Américas. El interlocutor responde de forma breve y concisa cómo encontrar el lugar. El contenido se realizó por el mismo sujeto femenino para la grabación en maya, español e inglés, mientras que el protagonista principal hizo la grabación en español y maya como primera lengua, y en inglés como lengua extranjera, es decir, un sujeto masculino habló las tres lenguas. Las otras grabaciones que forman los distractores fueron una en español, otra en maya y otra en inglés, realizadas por mujeres y hombres distintos por cada lengua.

A los participantes se les presentaron las seis grabaciones de forma continua, una detrás de otra (ver tabla 3).

\begin{tabular}{|c|c|c|c|c|c|}
\hline A & B & C & D & E & F \\
\hline $\begin{array}{c}\text { Grabación } \\
\text { en maya } \\
\text { del trío } \\
\text { oculto. }\end{array}$ & $\begin{array}{c}\text { Grabación } \\
\text { en español } \\
\text { como } \\
\text { distractor. }\end{array}$ & $\begin{array}{c}\text { Grabación } \\
\text { en inglés } \\
\text { del trío } \\
\text { oculto. }\end{array}$ & $\begin{array}{c}\text { Grabación } \\
\text { en español del } \\
\text { trío oculto. }\end{array}$ & $\begin{array}{c}\text { Grabación } \\
\text { en maya como } \\
\text { distractor. }\end{array}$ & $\begin{array}{c}\text { Grabación } \\
\text { en inglés } \\
\text { como } \\
\text { distractor. }\end{array}$ \\
\hline
\end{tabular}

TABLA 3. Cada una de las voces evaluadas.

Posteriormente, escucharon de nuevo las grabaciones, una por una, prestando atención a la voz masculina, y al final de cada grabación procedieron a responder 16 reactivos con base en una escala (ver el test en el anexo C). Este test fue adaptado de otros similares usados en estudios previos (Loureiro-Rodríguez, Bogess y Goldsmith, 2012, Real Academia Galega).

Por nuestra parte, elegimos para este estudio un instrumento orientado a la parte afectiva, pues esto nos permitirá realizar una introspección de algunas de las actitudes en la región peninsular y determinar percepciones hacia los hablantes de maya, español e inglés. Además, nuestra intención fue probar qué tanto este conjunto de preguntas podrían aplicarse a la población peninsular de las ciudades estudiadas. Sin embargo, consideramos que en otro estudio este cuestionario de tipo afectivo podría adaptarse a cuestiones valorativas locales más enfocadas en lo típicamente maya yucateco, lo campechano y lo quintanarroense.

En la parte superior del test cada letra representa una grabación y una persona diferente que habla español, o maya, o inglés. Aparece la pregunta y el informante elige su respuesta marcando con una "x", en una escala del 1 al 6 , siendo 1 el valor más alto y 6 el más bajo.

\footnotetext{
${ }^{7}$ Se ha sugerido que cuando se realizan grabaciones para ser aplicadas como matched-guise, participe el género opuesto al protagonista que será evaluado, con el fin de facilitar el trabajo del juez que evalúa, ya que si en una grabación están presentes dos mujeres, resulta más complicado decirle al informante: "Evalúa a la primera mujer o a la que dijo aquello". En cambio, si la grabación incluye un hombre y una mujer, es más fácil solicitarle que evalúe al hombre sin que tenga que llevar a cabo un ejercicio de discriminación de otros hombres, o, al revés si fuera una grabación de dos mujeres.
} 
Para sistematizar los resultados se usó el Programa Estadístico para las Ciencias Sociales (SPSS) (Statistical Package for the Social Sciences), con el cual se obtuvieron las estadísticas descriptivas, y se usaron pruebas ANOVA y pruebas T para comparar los resultados de los dos grupos de hablantes: maya o español.

\section{Actitudes hacia la lengua maya, el español y el inglés. Resultados}

Retomando la primera pregunta que dirige el estudio: ¿cuáles son las actitudes de tres sectores de población urbana de la península de Yucatán hacia la lengua maya, el español y el inglés?, los resultados evidencian actitudes diferentes en los tres grupos. En el anexo B se muestra una tabla con las frecuencias y medidas de tendencia central por cada voz que fue evaluada ${ }^{8}$ en las tres ciudades y según los reactivos (preguntas) que se usaron para la evaluación de cada grabación (anexo C).

A continuación presentamos los datos relevantes y significativos del trío oculto únicamente, pues sobre ellos queremos centrar el análisis, considerando que son el reflector principal de la prueba. Para comenzar, analizaremos las actitudes hacia el hablante maya del trío oculto.

\section{Hablante de maya}

En la tabla 4 se desglosan los resultados relevantes, considerando los promedios de los valores asignados por todos los informantes en cada ciudad (anexo D).

\begin{tabular}{|l|c|c|c|c|c|c|c|}
\hline & $\begin{array}{c}\text { Atractivo } \\
\text { G4 }\end{array}$ & $\begin{array}{c}\text { Gracioso } \\
\text { G13 }\end{array}$ & $\begin{array}{c}\text { Inteligente } \\
\text { G1 }\end{array}$ & $\begin{array}{c}\text { Amigable } \\
\text { G2 }\end{array}$ & $\begin{array}{c}\text { Generoso } \\
\text { G11 }\end{array}$ & $\begin{array}{c}\text { Acepta } \\
\text { nuevas } \\
\text { costumbres } \\
\text { G10 }\end{array}$ & $\begin{array}{c}\text { Mentalidad } \\
\text { abierta } \\
\text { G8 }\end{array}$ \\
\hline Chetumal & 4.1 & 3.6 & 2.8 & 2.8 & 3.2 & 3.8 & 3.6 \\
\hline Cancún & 3.4 & 3.4 & 1.7 & 2.3 & 2.3 & 3 & 2.8 \\
\hline Mérida & 3.8 & 3.7 & 3.3 & 2.9 & 2.5 & 2.8 & 2.8 \\
\hline
\end{tabular}

TABLA 4. Valores relevantes hacia el hablante de maya.

Si consideramos los promedios más altos y más bajos para las cualidades, observamos que, aunque cada grupo muestra un rango diferente, las características de atractivo y gracioso aparecen en los tres grupos entre las valoraciones de las escalas más altas tendientes hacia la derecha (recordemos que el 1 significa + adjetivo y

\footnotetext{
${ }^{8}$ Nos referimos a cada una de las seis voces evaluadas, presentadas en la tabla 3 en la sección de método.
} 
el 6 es - adjetivo); mientras que inteligente y amigable cuentan con los números en la escala más bajos tendientes hacia la izquierda, 1 en Cancún y en Chetumal, pero no en Mérida. La generosidad aparece en Cancún y en Mérida con valores más positivos, pero en Chetumal fue un juicio más neutro (3.2). Sobresale también el contraste entre Mérida y Chetumal respecto a las cualidades acepta nuevas costumbres y mentalidad abierta, ya que en la primera los promedios muestran tendencias más positivas o neutras, mientras que en Chetumal parecen proclives a estimaciones más negativas (aproximándose a 4).

Hablante de inglés

Ahora veamos el siguiente concentrado de los datos más relevantes sobre el hablante de inglés del trío oculto.

\begin{tabular}{|l|c|c|c|c|c|c|}
\hline & $\begin{array}{c}\text { Interesado } \\
\text { en } \\
\text { progresar } \\
\text { G7 }\end{array}$ & $\begin{array}{c}\text { Buen nivel } \\
\text { de estudios } \\
\text { G3 }\end{array}$ & $\begin{array}{c}\text { Mentalidad } \\
\text { abierta } \\
\text { G8 }\end{array}$ & $\begin{array}{c}\text { Amigable } \\
\text { G2 }\end{array}$ & $\begin{array}{c}\text { Fiel } \\
\text { G16 }\end{array}$ & $\begin{array}{c}\text { Atractivo } \\
\text { G4 }\end{array}$ \\
\hline Chetumal & 2.5 & 2.6 & 2.8 & 3 & 4.1 & 3.2 \\
\hline Cancún & 1.8 & 2 & 2.3 & 2 & 2.7 & 3.4 \\
\hline Mérida & 2.5 & 2.5 & 2.2 & 2.1 & 3.4 & 3.1 \\
\hline
\end{tabular}

TABLA 5. Valores relevantes hacia el hablante de inglés.

Como se observa en la tabla, la característica con puntajes más positivos, y que es compartida por Cancún y Chetumal, es interesado en progresar, seguida por buen nivel de estudios. Mentalidad abierta fue otra cualidad valorada más positivamente en Chetumal y Mérida, en tanto que amigable lo fue en Cancún y en Mérida. Las valoraciones más tendientes a la derecha (- adjetivo) fueron fiel en Chetumal y Mérida, y atractivo en Cancún y Mérida, aunque son neutras en el rango en general.

Hablante de español

Veamos a continuación los valores relevantes expresados hacia el hablante de español en las tres ciudades.

Como podemos ver, una característica común en los tres grupos urbanos con los promedios más bajos (+ adjetivo o atributo) es buen nivel de estudios; sin embargo, mientras que para Cancún y Mérida los promedios son positivos, para Chetumal el valor es neutro (3.2). Otra cualidad compartida, pero esta vez sólo por Cancún y Mérida, es la de confianza en sí mismo, con valores tendientes a positivos. Mentalidad abierta también aparece con los promedios más bajos (+ adjetivo o atributo) en Chetumal y Mérida, aunque sean valores más bien neutros en la escala general. Inteligente aparece en Cancún y Chetumal, pero su valor es positivo en el 
primero y neutro en el segundo. Las características con valores más alejados del 1 fueron atractivo, gracioso y fiel. La primera en Cancún (valores más bien neutros) y Chetumal (valores negativos); la segunda en Cancún y Mérida (neutros y negativos), y la tercera en Chetumal y Mérida (ambos negativos).

\begin{tabular}{|l|c|c|c|c|c|c|c|}
\hline & $\begin{array}{c}\text { Buen nivel } \\
\text { de estudios } \\
\text { G3 }\end{array}$ & $\begin{array}{c}\text { Confianza } \\
\text { en sí mismo } \\
\text { G9 }\end{array}$ & $\begin{array}{c}\text { Mentalidad } \\
\text { abierta } \\
\text { G8 }\end{array}$ & $\begin{array}{c}\text { Inteligente } \\
\text { G1 }\end{array}$ & $\begin{array}{c}\text { Atractivo } \\
\text { G4 }\end{array}$ & $\begin{array}{c}\text { Gracioso } \\
\text { G13 }\end{array}$ & $\begin{array}{c}\text { Fiel } \\
\text { G16 }\end{array}$ \\
\hline Chetumal & 3.2 & 3.4 & 3.5 & 3.1 & 3.9 & 3.4 & 4.2 \\
\hline Cancún & 1.9 & 1.8 & 2 & 1.8 & 2.6 & 2.7 & 2.6 \\
\hline Mérida & 2.4 & 2 & 2.6 & 2.7 & 2.9 & 3.5 & 3.5 \\
\hline
\end{tabular}

TABLA 6. Valores relevantes hacia el hablante de español.

Cualidades compartidas y particulares por cada hablante

Por otro lado, si agrupamos a los hablantes por lengua y analizamos los datos, hay tres cualidades compartidas, aunque con distinto grado. Una de ellas es atractivo, la cual aparece en los tres grupos. Esta cualidad muestra una tendencia a valores negativos (- adjetivo) para los hablantes mayas (con una excepción neutra), a valores neutros para los hispanohablantes (con una excepción negativa), y a valores neutros también para los anglohablantes (con una excepción positiva).

Otra cualidad que coincidió fue inteligente, pero esta vez sólo con el mayahablante e hispanohablante, y dada por Cancún y Chetumal. El hablante de maya recibió valores positivos en ambos lugares (+ adjetivo). Algo similar ocurrió con el hablante de español, salvo en la ciudad de Chetumal, donde recibió un valor neutro.

Amigable también fue otra característica que surgió con el mayahablante y con el anglohablante; con valores positivos para todos, pero el primero recibió esta valoración en Cancún y en Chetumal, y el hablante de inglés en Cancún y Mérida. Se identificaron también características específicas asociadas con hablantes de la misma lengua. Para el mayahablante se asociaron generoso, inteligente y amigable con valores positivos en general (aunque no en todos los grupos); atractivo con valores negativos en su mayoría, mientras que acepta nuevas costumbres fue contrastivo con valor negativo en Chetumal, pero positivo en Mérida. Mentalidad abierta tuvo valoración neutra en Cancún, pero negativa en Chetumal.

En el caso particular del hispanohablante, sobresalen las cualidades de buen nivel de estudios y confianza en sí mismo con valoraciones positivas en Cancún y en Mérida, en tanto que en Chetumal son neutras. Otras cualidades que destacan son gracioso y fiel, pero reciben valoraciones negativas y neutras.

Para el anglohablante, interesado en progresar es la asociada principalmente con valores positivos. Amigable también es positivo, pero sólo en Cancún y en Mérida. Una de las cualidades con valores más tendientes a la derecha fue atractivo, con valores neutros y negativos por el grupo de Chetumal. 
Diferencias significativas mediante pruebas ANOVA y Scheffe

Para comprobar si existen diferencias de juicios entre los tres grupos, se realizó una prueba ANOVA, y una prueba Scheffe para identificar el/los grupos que no se comportan igual. Presentamos los resultados significativos por hablante y por grupo.

Respecto al hablante maya (gráfica 1), tenemos que, según la prueba Scheffe, Cancún presenta una diferencia significativa en relación con los otros grupos en cuanto a la cualidad de inteligencia con valores más próximos al 1 (+ adjetivo), siendo ligeramente mayor la diferencia con Mérida que con Chetumal. La siguiente característica relevante fue el nivel de estudios que, de acuerdo con la prueba post hoc Scheffe, muestra diferencias importantes entre los grupos: Mérida presenta mayor distanciamiento hacia valores negativos (promedio de 3.8), seguido de Chetumal (3.5), y Cancún es el más favorable (2.4). Otra característica representativa fue puede ser líder, la cual resulta muy diferente entre Cancún (2.4 promedio) y Chetumal (3.6 promedio), siendo positivas las valoraciones en Cancún y tendientes a negativas en Chetumal; en Mérida la diferencia no resultó significativa. Finalmente, fiel también muestra evidencia de haber recibido valores muy diferentes entre Cancún y Chetumal, con promedios positivos (+ adjetivo) en el primero (2.5) y tendientes a negativos (- adjetivo) en el segundo (3.9). Esto se resume en la siguiente gráfica:

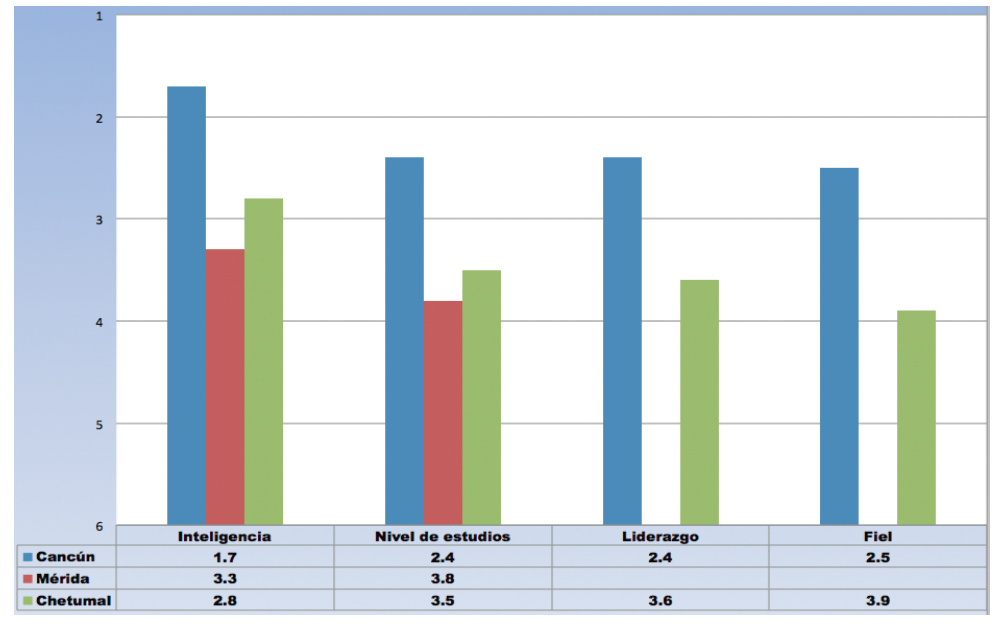

GráfICA 1. Diferencias significativas. Hablante de maya.

En el caso del hablante de inglés (gráfica 2), las características que muestran diferencias entre los grupos, según la prueba post hoc, fueron amigable, confiable, generoso, trabajador y fiel. Respecto a las primeras cuatro, Chetumal muestra juicios diferentes (neutros) en relación con Cancún y Mérida, donde las valoraciones son 
positivas. Fiel muestra diferencias entre Cancún y Chetumal, el primero con tendencias más bien positivas, y el segundo, negativas. En Mérida son neutras.

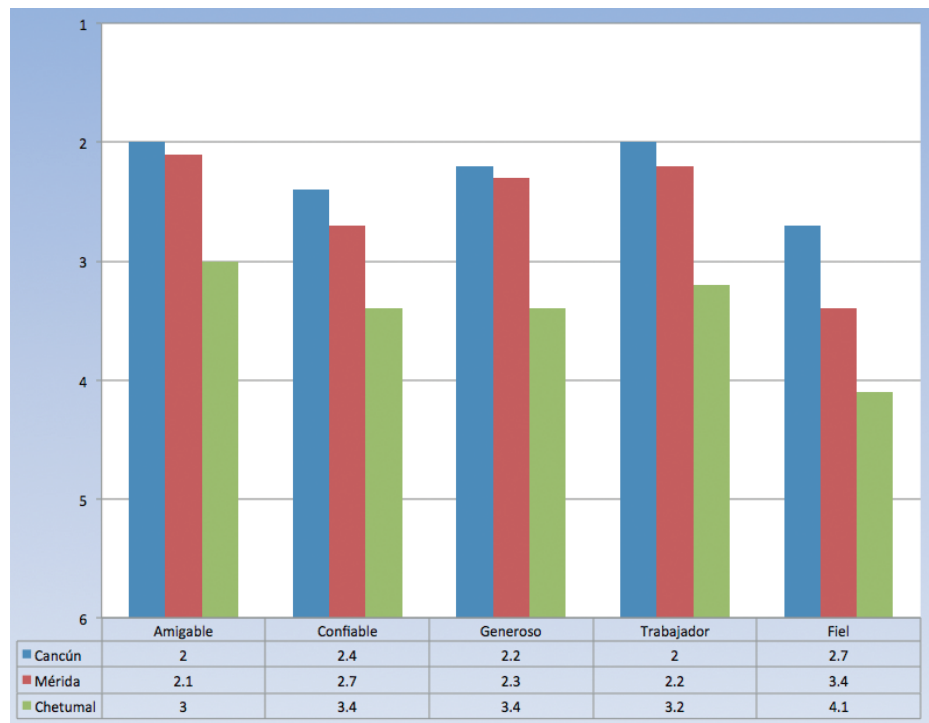

GrÁfICA 2. Diferencias significativas. Hablante de inglés.

Las cualidades disímiles identificadas con la prueba post hoc para el hablante de español (gráfica 3) fueron inteligente, amigable, buen nivel de estudios, atractivo, confiable, sentido del humor, mentalidad abierta, confianza en sí mismo, generoso, puede ser líder, trabajador y fiel. Respecto a inteligente, amigable y buen nivel de estudios, la diferencia es clara entre Cancún y Chetumal, pues el primero muestra valores positivos y el segundo neutros. Mérida, por su parte, presenta también tendencias positivas, pero menos favorables que Cancún.

Atractivo presenta diferencias significativas entre Cancún (2.6) y Chetumal (3.9) nuevamente con valores positivos para el primero y tendientes a negativo para el segundo. En Mérida parecen más neutros. Confiable, sentido del humor y mentalidad abierta también son otras cualidades con valores claramente distintos en Chetumal y en Cancún, siendo positivos en el último y tendientes a negativos en el primero. Mérida se mantiene con valores más bien neutros.

Para las características confianza en sí mismo y generoso, el resultado de la prueba Scheffe muestra que Chetumal difiere de Mérida y Cancún, ya que sus juicios son tendientes a negativos, mientras que en los otros grupos éstos son positivos.

En el caso de puede ser líder, Chetumal refleja valores tendientes a negativos, y los otros grupos, neutros. Trabajador presenta valoraciones positivas en Cancún, pero neutras en los otros grupos. Finalmente, se observa una diferencia significativa entre Cancún y Chetumal respecto a fiel; valores positivos en el primero y negativos en el segundo. En Mérida son neutros, según nuestro rango. 


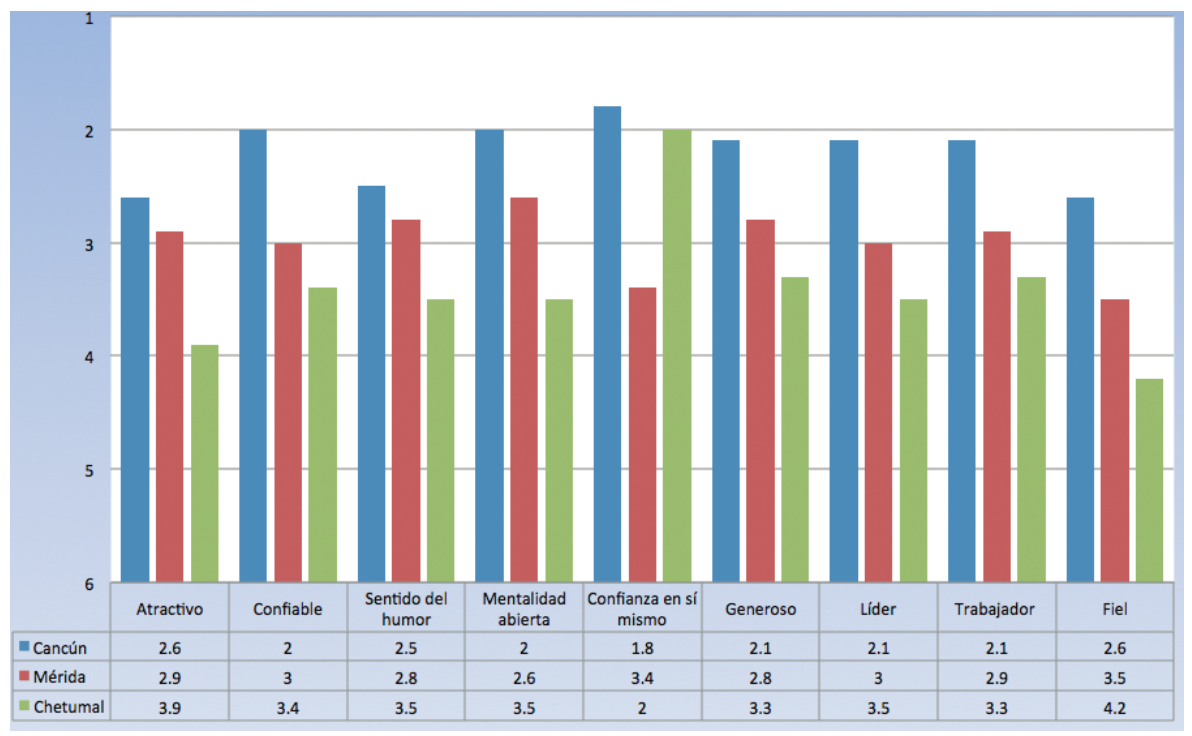

GráFICA 3. Diferencias significativas. Hablante de español.

Analizando todos estos datos se aprecia que algunas características difirieron significativamente entre los grupos. Así, resulta interesante que con el mayahablante las diferencias se establecieron en torno a inteligencia, puede ser líder y fiel. Cancún manifiesta en todos los casos promedios positivos, seguido de Mérida, con más neutros, y al final Chetumal con, incluso, valores negativos.

Para los hablantes de español, las cualidades asociadas y que difieren entre los grupos son buen nivel de estudios, confianza en sí mismo, puede ser líder y fiel. También aparecieron, con una mención, acepta nuevos y usos y costumbres y con mentalidad abierta, cualidades que se pueden asociar semánticamente. Una vez más, Cancún cuenta con valoraciones positivas, seguido de Mérida con una mezcla de promedios positivos y neutros; Chetumal, por su parte, ofrece en general valores neutros.

El hablante de inglés, por su parte, sólo causó diferencias entre los grupos en dos características: confiable y fiel. Cancún y Mérida se comportaron de manera muy similar al respecto, con valores muy positivos, mientras que los de Chetumal fueron, en su mayoría, neutros.

Pruebas-T, variables significativas

Para comprobar si el sexo, la edad y el bilingüismo tenían algún efecto en los juicios, se realizaron pruebas $\mathrm{T}$. Ni el sexo ni la edad resultaron significativas, pero la distinción monolingüismo versus bilingüismo de los informantes-jueces sí muestra diferencias importantes. 
Para el hablante maya, resultaron representativas confiable (.016), sentido del humor (.005), interesado en progresar (.006), confianza en sí mismo (.020), acepta nuevos usos y costumbres (.016), puede ser líder (.045) y fiel (.005). Excepto por confianza en sí mismo, puede ser líder y fiel, los bilingües ofrecieron valores más próximos a la izquierda (juicios más positivos) que los monolingües.

En el caso del hablante de inglés, la prueba arrojó diferencias significativas para inteligente (.035), sentido del humor (.039), interesado en progresar (.047), gracioso (.016) y fiel (.017). Excepto por sentido del humor, el resto de los bilingües obtiene promedios más cercanos a la izquierda (juicios más positivos) que los monolingües.

Continuando con el hablante de español, sólo inteligente, con (.05), resultó significativo, siendo los bilingües los que le daban valores en promedio (1.3) más cercanos a la izquierda que los monolingües (1.5).

\section{Las actitudes hacia la lengua maya, el español y el inglés. Discusión}

De lo anterior podemos observar que los informantes de Cancún y Mérida muestran, en general, actitudes más positivas hacia las tres lenguas. Chetumal presenta valoraciones más neutras hacia el español, e incluso negativas para el maya y el inglés. Quizás estas diferencias ocurran por las divergencias de población, sus actividades económicas, sus antecedentes sociales e históricos. Mientras que Mérida y Cancún se han convertido en polos de atracción turísticos y el nuevo hogar de muchos migrantes nacionales e internacionales y, por tanto, en lugares trilinguies, a Chetumal han emigrado más recientemente sobre todo nacionales no mayas. Por otra parte, las actitudes negativas hacia el inglés de los vecinos beliceños (que se evidencia en la calle o en conversaciones personales) probablemente tengan un efecto en estos resultados (no tan positivos).

De esta manera, observamos que, ante la globalización y la vocación turística de Mérida y Cancún, es vital la incorporación del inglés en muchos ámbitos de la vida actual. ${ }^{9} \mathrm{Si}$ bien es cierto también que el inglés es uno de los idiomas que genera el desplazamiento del maya en el contexto de enseñanza de segundas lenguas, no se ha considerado el valor afectivo que tiene junto al maya, pues es común en los testimonios de los habitantes de la zona peninsular la expresión de ideas como: "El que sabe maya, fácilmente aprende inglés", "Ahora en las escuelas se está enseñando maya e inglés", "Tienes que aprender maya e inglés", "Si sabes español, maya e inglés, donde sea te mueves y vas", "Claro, si sabes hablar español, maya e inglés; nadie te engaña", "Si sabes maya, vas a un pueblo, y si sabes inglés, vas a los Estados Unidos” (apud Sima Lozano, 2012).

\footnotetext{
${ }^{9}$ Según Pfeiler, Franks y Briceño Enrique (1990: 53), en Mérida "las actitudes hacia el inglés son muy positivas y la mayoría piensa que es el idioma del futuro y una lengua indispensable, internacional e importantísima para el comercio. [...] Sin excepción, todos los entrevistados que aún no lo saben hablar demostraron gran interés por aprenderlo".
} 
Se debe aprovechar que las actitudes actuales que reportan los hablantes de la región sean heterogéneas hacia una lengua y otra. Retomando los tres componentes de las actitudes (cognitivo, afectivo y conductual), notamos posibles ventajas que tienen cada uno de los idiomas. El inglés permite conseguir mejores trabajos y mayor remuneración económica, por lo que los hablantes optan por aprender esta lengua extranjera. ${ }^{10}$ Aquí vemos la fuerza del componente conductual, pero cuando se trata de la relación con la identidad, la historia, la cultura, lo regional, el idioma maya tiene ventajas con el componente afectivo. En cuanto al español, llama la atención que, si bien es una lengua que ha desplazado al maya, en la parte afectiva se le considera lo común, pues como evidencia empírica se escuchan ideas respecto a la lengua española como: "Algo cualquiera", "Lo que sea", "Lo que todos hablan y dicen", "Lo normal" (componente cognitivo). En consecuencia, parece existir un desequilibrio de las actitudes hacia el español.

Es así que las inminentes políticas del lenguaje en esta región, en este caso, se enfrentan con una mayor complejidad al tratar con una relación de trilingüismo (ver Sima Lozano y Perales Escudero, 2015), dentro de una configuración sociolinguíística en conflicto, en la que el español y el inglés desplazan al idioma maya principalmente, pero dentro de una postura psicosocial en la que las actitudes afectivas reflejan el aprecio por el maya y el inglés, pero no tanto por el español, a pesar de que ha convivido en una situación de diglosia con la lengua maya. ${ }^{11}$

\section{Breve autocrítica hacia la técnica del matched-guise}

Por lo que respecta a la segunda pregunta de investigación: ¿qué ventajas o desventajas tiene el instrumento del matched-guise en su aplicación al estudio de actitudes linguísticas en la región?, encontramos que el uso del instrumento en términos metodológicos permite la tabulación y agrupación de los datos de forma sistemática, pues en términos cuantitativos puede realizarse un análisis estadístico siguiendo el programa del SPSS, tal como se hizo en este trabajo.

Por otro lado, la aplicación del instrumento en la población atrajo la atención de los participantes, quienes lo consideraron muy novedoso. Una de las desventajas radicó en la provisión de las instrucciones a los informantes y en el tiempo que se requiere para realizar la tarea. Adicionalmente, la evaluación de 16 reactivos para seis voces resultó un proceso largo, que puede aburrir y distraer

${ }^{10}$ En un trabajo de campo que se aplicó en las comunidades de Dzitas y Xocen, Terborg y Velázquez Vilchis (2005: 49) mencionan: "Entre la gente no sólo existía el fuerte deseo de que sus hijos hablaran bien el español. También se demostraba admiración por el inglés".

${ }^{11}$ Canché Teh, Pfeiler y Carrillo Carreón (2010) han referido que la situación del español y la lengua maya en Yucatán es de "bilingüismo diglósico de adscripción con patrones de diglosia". Esto significa que cada una de las lenguas tiene diferentes funciones, pues es la dinámica social la que determina el uso de una u otra lengua. 
al informante. En realidad, se observó que tanto las indicaciones como la propia evaluación para personas con un nivel de instrucción bajo y mayores de edad resultan difíciles de procesar en poco tiempo.

Para completar la respuesta a la segunda pregunta de investigación, una de las oportunidades que se presenta es la inclusión de tres lenguas dentro de una prueba de matched-guise, situación que por las circunstancias propias de la región permite la relación de maya, español e inglés, idiomas con los que los hablantes de la zona están familiarizados, por lo que se debe aprovechar el saber de los idiomas que se usan en una región para incluirlos en esta técnica. ${ }^{12}$

En cuanto al tema de la grabación, la pregunta sobre cómo llegar a Plaza las Américas generó que los participantes se sintieran identificados con el lugar y les resultara una situación común y neutral, lo que le puede ocurrir a cualquiera de los informantes que use alguna de las tres lenguas.

Una limitante que posiblemente afectó los resultados, en particular los de los bilingües de maya-español, fue que las voces grabadas correspondían a hablantes de una variante de maya de Quintana Roo y no se incluyó alguna variante de Yucatán. Sin embargo, este problema parece insalvable en este tipo de estudios, pues es imposible incluir todas las variantes dialectales (aun dentro de un mismo estado puede haber distintas). Una mayor inclusión de variantes sería recomendable en futuros estudios.

Por el lado de las preguntas del test, éstas no generaron problemática alguna de entendimiento por parte de los participantes en el estudio, pero, como dijimos en la parte correspondiente a la sección del método, el instrumento podría adaptarse con valores regionales en otro trabajo, lo cual incidiría en probar un matched-guise de tipo más local.

\section{Conclusiones}

Como vimos en el análisis cuantitativo, cada ciudad valora de manera diferenciada las lenguas en contacto. Así, Cancún es la más abierta y con actitudes más positivas hacia los tres idiomas, seguida de Mérida, y en tercer lugar, Chetumal, que llamó la atención porque genera valores negativos para los hablantes del maya y también para los anglohablantes, por lo que proponemos que en futuros estudios se incorporen perspectivas históricas y migratorias para explicar estas actitudes diferenciadas hacia los idiomas, pues la historia de cada espacio es un punto de partida para comprender el presente.

Cabe señalar que hace falta más investigación sobre las lenguas en contacto en la región, ya que la mayoría de los estudios de mantenimiento y desplazamiento de lenguas realizados en la península se ha centrado en el maya

\footnotetext{
${ }^{12}$ Por saber nos referimos no al conocimiento o competencia de la lengua, sino a la conciencia de la existencia y el uso de los idiomas referidos en la región.
} 
yucateco, pero se requieren investigaciones que expliquen el mismo problema atendiendo una relación recíproca con el español yucateco y el inglés. Asimismo es evidente una ausencia de políticas linguísticas para la convivencia de las tres lenguas, por lo que estudios como estos podrían ayudar al desarrollo de las mismas.

Finalmente, la técnica del matched-guise parece ser un instrumento útil para recoger las actitudes de los informantes. Es necesario, sin embargo, revisar y actualizar los elementos evaluados y adaptarlos a la comunidad de habla en cuestión atendiendo aspectos culturales, sociales y particulares. Asimismo, con el objeto de hacerlo más eficaz, conviene revisar el proceso de la tarea con los informantes. 


\section{BIBLIOGRAFÍA}

Álvarez Murillo, Edna

2008 "Estudio de actitudes lingüísticas maya-español a través del análisis del discurso en Holcá, Yucatán”, tesis de maestría en Antropología. México: Universidad Nacional Autónoma de México, Facultad de Filosofía y Letras.

Baker, Colin

1992 Attitudes and Language. Clevedon, Philadelphia, Adelaide: Multilingual Matters LTD.

Barragán Trejo, Daniel

2006 "Si no la haces, ¿de qué vives? Migrantes mi’phàà (tlapanecos de Tlacoapa) en Tlaquepaque: un desplazamiento linguístico en proceso", tesis de maestría en Linguística Aplicada. Guadalajara: Universidad de Guadalajara.

2009 "Si no la haces, ¿de qué vives? Le vamos a enseñar poco tlapaneco: un desplazamiento linguístico en proceso entre migrantes mi'phaa (tlapanecos de Tlacoapa) en Tlaquepaque, Jalisco, México", Cuadernos Interculturales, 7 (12): 21-46.

Be Ramírez, Pedro Antonio

En prensa "Migrantes yucatecos, itinerarios transnacionales y aprendizajes: la experiencia desde un escenario turístico", Cuicuilco.

Blas Arroyo, José Luis

1999 "Las actitudes hacia la variación intradialectal en la sociolinguiística hispánica”, Estudios Filológicos, 34: 47-72.

Canché Teh, Flor, Barbara Pfeiler y Carlos Carrillo Carreón

2010 "La familia extensa como promotora de la vitalidad del maya", Etnia, lengua y territorio, El sureste ante la globalización, pp. 237-250. Ricardo López (coord.). Mérida: Universidad Nacional Autónoma de México, Centro Peninsular en Humanidades y Ciencias Sociales.

Castillo Hernández, Mario Alberto

2007 Mismo mexicano pero diferente idioma: Identidades y actitudes lingüísticas en los maseualmej de Cuetzalan. México: Universidad Nacional Autónoma de México, Instituto de Investigaciones Antropológicas.

Durán Caballero, José Enrique y Julio Enrique Sauma Castillo

2003 "Actitudes hacia la enseñanza de la lengua maya en el municipio de Mérida, Yucatán: Un estudio desde la perspectiva de la Sociología del lenguaje”, tesis de licenciatura en Antropología. Mérida: Universidad Autónoma de Yucatán.

Fishman, Joshua

1974 "Conservación y desplazamiento del idioma como campo de investigación (Reexamen)”, Antología de Estudios de etnolingüística y sociolingüística, pp. 375- 
423, Paul Garvin y Yolanda Lastra (coords.). México: Universidad Nacional Autónoma de México, Instituto de Investigaciones Antropológicas.

1979 Sociología del lenguaje, Ramón Sarmiento y Juan Carlos Moreno (trads.). Ma[1972] drid: Ediciones Cátedra.

1991 Reversing Language Shift. Theoretical and Empirical Foundations of Assistance to Threatened Languages. Clevedon: Multilingual Matters Ltd.

Fortuny Loret de Mola, Patricia

2004 "Transnational hetzmek: entre Oxkutzcab y San Pancho", Estrategias identitarias. Educación y la antropología histórica en Yucatán, pp. 225-254, Juan A. Castilllo Cocom y Quetzil E. Castaneda (eds.). Mérida: Universidad Pedagógica Nacional, The Open School of Etnography and Anthropology (OSEA) y Secretaría de Educación Pública.

González Martínez, Juan

2008 "Metodología para el estudio de las actitudes linguíísticas", Actas del XXXVII Simposio Internacional de la Sociedad Española de Lingüística (SEL), pp. 229-238, I. Olza Moreno, M. Casado Velarde y R. González Ruiz (eds.). Navarra: Servicio de Publicaciones de la Universidad de Navarra.

Haugen, Einar

1978 "Bilingualism, Language Contact, an Inmigrant Languages in the United States: A Research Report 1956-1970", Advances in the Study of Societal Multilingualism, pp. 1-112, Joshua Fishman (ed.). The Hague: Mouton.

Instituto Nacional de Estadística, Geografía e Informática

2010a <http://cuentame.inegi.gob.mx/monografias/informacion/qroo/default. aspx?tema $=$ me\&e $=23>($ Consultada el 11 de mayo de 2015).

2010b < http://cuentame.inegi.org.mx/monografias/informacion/yuc/default. aspx?tema $=$ me\&e $=31>($ Consultada el 11 de mayo de 2015).

2010c <http://cuentame.inegi.org.mx/poblacion/default.aspx?tema $=$ P $>$ (Consultada el 10 de junio de 2015).

2010d < http://cuentame.inegi.org.mx/monografias/informacion/QRoo/Poblacion/ default.aspx tema $=$ ME\&e $=23>$ (Consultada el 5 de junio de 2015).

2011a <http:/www.inegi.org.mx/prod_serv/contenidos/espanol/bvinegi/productos/ censos/poblacion/2010/panora_socio/yuc/Panorama_Yuc.pdf $>$ (Consultada el 11 de mayo de 2015).

2011b Principales resultados del Censo de Población y Vivienda 2010. Quintana Roo. México: Instituto Nacional de Estadística, Geografía e Informática.

2014 Anuario estadístico y geográfico de Quintana Roo 2014. México: Instituto Nacional de Estadística, Geografía e Informática.

Jiménez Peraza, Pedro César

1982 Lealtad hacia la lengua maya. México: Secretaría de Educación e Instituto Nacional Indigenista.

Lambert, Wallace E.

1967 “A Social Psychology of Bilingualism”, Journal of Social Issues, 23 (2): 91-109. 
Lastra, Yolanda

1992 Sociolingüística para hispanoamericanos. Una introducción. México: El Colegio de México.

Lavandera, Beatriz

1978 "Where does the Sociolinguistic Variable Stop?", Language in Society, 7: 171182.

León-Portilla, Miguel

2004 "El destino de las lenguas indígenas de México", De historiografía lingüística e historia de las lenguas, pp. 51-70, Ignacio Guzmán Betancourt, Pilar Máynez y Ascensión H. de León Portilla (coords.). México: Universidad Nacional Autónoma de México y Siglo XXI Editores.

Loureiro Rodriguez, Verónica, May M. Bogess and Anne Goldsmith

2012 "Language Attitudes in Galicia: Using the Matched-Guise Test Among High School Students", Journal of Multilingual and Multicultural Development, 34 (2): $1-18$.

Nettle, Daniel and Suzanne Romaine

2000 Vanishing Voices: the Extinction of the World's Languages. New York: Oxford University Press.

Pfeiler, Barbara

1993 "La lealtad lingüística del indígena maya yucateco. Validación de la prueba de matched-guise", Estudios de Lingüística Aplicada, 11 (17): 82-93.

1999 "Situación sociolinguiística. Cap. IV, I", Atlas de Procesos Territoriales de Yucatán, pp. 269-299, Enrique Urzais Lares (coord.). México: Ed. PROESA, Proyección Cartográfica.

Pfeiler, Barbara, Anne Franks y Enrique Martín Briceño

1990 "El maya y el inglés en la nomenclatura de los comercios meridanos", Revista de la Universidad Autónoma de Yucatán, 5 (174): 49-54.

Real Academia Galega

$<$ http://www.gencat.cat/llengua/noves/noves/hm02hivern/internacional/galego2_4.htm> (Consultada el 20 de junio de 2015).

Rico Lemus, Gabriel

2010 "Mantenimiento y resistencia de la lengua p'urhépecha en Santa Fe de la Laguna, Michoacán”, tesis de maestría en Linguiística. México: Universidad Nacional Autónoma de México, Facultad de Filosofía y Letras.

Sánchez Arroba, María Elena

2009 "Migración y pérdida de la lengua maya en Quintana Roo", Migración y políticas públicas, pp. 397-468, Martín Saúl Vargas Paredes (coord.). México: Cámara de Diputados, Universidad de Quintana Roo y Miguel Ángel Porrúa. 
Silva-Corvalán, Carmen

1986 "Bilingualism and Language Change: the Extension of estar in Los Angeles". Language, 62 (3): 587-608.

Sima Lozano, Eyder Gabriel

2011 "Actitudes de monolingües de español hacia la maya y sus hablantes en Mérida”, Ketzalcalli, 61-80.

2012 "Actitudes hacia la lengua maya de un sector de población de la ciudad de Mérida”, tesis de doctorado en Antropología. México: Universidad Nacional Autónoma de México, Facultad de Filosofía y Letras.

Sima Lozano, Eyder Gabriel y Moisés Damián Perales Escudero

2015 "Actitudes linguísticas hacia la maya y la elección del aprendizaje de un idioma en un sector de población joven de la ciudad de Mérida”, Península, 10 (1): $121-144$.

Sima Lozano, Eyder Gabriel, Moisés Damián Perales Escudero y Pedro Antonio Be Ramírez 2014 "Actitudes de yucatecos bilingües de maya y español y sus hablantes en Mérida, Yucatán”, Estudios de Cultura Maya, 43: 157-179.

Terborg, Roland

2004 "El desplazamiento del otomí en una comunidad del municipio de Toluca", tesis de doctorado en Linguiística. México: Universidad Nacional Autónoma de México, Facultad de Filosofía y Letras.

2006 "La ecología de presiones en el desplazamiento de las lenguas indígenas por el español. Presentación de un modelo", Forum: Qualitative Social Research, 7 (4): Art. 39, s. p., <http://www.qualitative-research.net/fqs-texte/4-06/06-439-s.htm> (Consultado el 18 de marzo de 2015).

Terborg, Roland y Laura García Landa

2011a "Las presiones que causan el desplazamiento-mantenimiento de las lenguas indígenas. La presentación de un modelo y su aplicación”, Muerte y vitalidad de las lenguas indígenas y las presiones sobre sus hablantes, pp. 29-61, Roland Terborg y Laura García Landa (coords.). México: Universidad Nacional Autónoma de México, Centro de Lenguas Extranjeras.

2011b "La máxima facilidad compartida como presión determinante", Muerte y vitalidad de las lenguas indígenas y las presiones sobre sus hablantes, pp. 259-273, Roland Terborg y Laura García Landa (coords.). México: Universidad Nacional Autónoma de México, Centro de Lenguas Extranjeras.

Terborg, Roland y Virma Velázquez Vilchis

2005 "Enseñanza de lenguas y su impacto en la ecología lingüística", Estudios de Lingüística Aplicada, 23 (41): 39-54.

2008 "La muerte de lenguas y la desventaja de ser nativo hablante del otomí en México", Universos, 5: 129-143. 
Trujillo Tamez, Alma Isela

2012 "La vitalidad linguiística de la lengua ayux ${ }^{13}$ o mixe en tres contextos: Tamazulapam del Espíritu Santo, San Lucas Camotlán y San Juan Guichicovi”, tesis de doctorado en Linguiística. México: Universidad Nacional Autónoma de México, Facultad de Filosofía y Letras.

${ }^{13}$ N. E. Así en el título de la tesis. Lo convencional es registrar dicho idioma como ayuuk o ayöök. 


\section{ANEXO A. GRABACIONES}

Grabación A en maya del trío oculto

- Mujer: Nojoch máak a wóojel bix u beytal in k'uchul Plaza las Americase? (Señor, ¿sabe cómo puedo llegar a Plaza las Américas?

- Hombre: Chen Kan a xímbalt ka’a p'éel esquinas ka wilik (Sólo vas a caminar dos esquinas, lo ves.)

Grabación B en español como distractor

- Mujer: Señor, ¿puede ayudarme a llegar a Plaza las Américas?

- Hombre: Está cerca de aquí, sólo caminas dos calles y lo verás.

Grabación C en inglés del trío oculto

- Mujer: Hello! Do you know how to get to Plaza Las Americas?

- Hombre: Yes, you have to walk three blocks to the right and you'll see it.

Grabación D en español del trío oculto

- Mujer: iHola! ¿Sabes cómo llegar a Plaza Las Américas?

- Hombre: Sí, mira, sólo caminas tres cuadras a la derecha y allí la verás.

Grabación E en maya como distractor

- Mujer: Xi'ipal ¿bix u beytal kin k'uchul Plaza las Americase'? (Muchacho cómo puedo llegar a Plaza las Américas)

- Hombre: Uach náats' te'ela' chen yaan a xímbaltik óoxp'eel tu'uk' ken ts'o'okoke' ka k'éechel ta no'oj (Está muy cerca por aquí, sólo vas a caminar tres esquinas, luego doblas a tu derecha).

Grabación F en inglés como distractor

- Mujer: Excuseme!, How do you get to Plaza Las Americas?

- Hombre: You need to get on bus that says Plaza Las Americas, and you need to get off at the stop where you see an office depot announcement. 


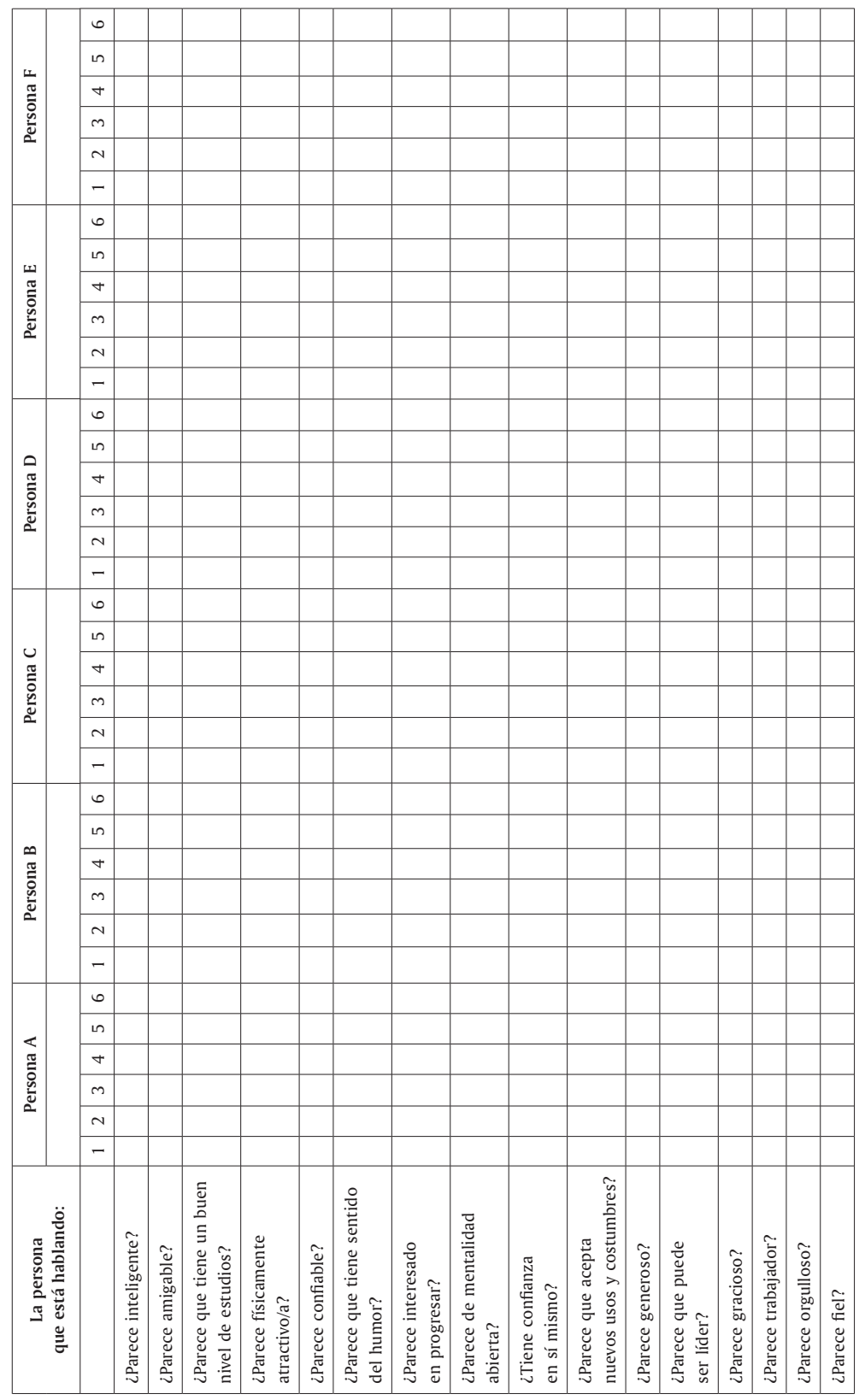




\section{ANEXO C. DESCRIPTIVOS VARIABLES DE LAS VOCES DE LOS HABLANTES QUE SE EVALUARON}

\begin{tabular}{|c|c|c|c|c|c|c|c|c|c|c|c|c|c|c|c|c|}
\hline & G-1 & G-2 & G-3 & $\mathrm{G}-4$ & G-5 & G-6 & G-7 & G-8 & G-9 & G-10 & G-11 & G-12 & G-13 & G-14 & G-15 & G-16 \\
\hline \multicolumn{17}{|c|}{$\begin{array}{l}\text { Hablante A } \\
\text { (maya del trío } \\
\text { oculto) }\end{array}$} \\
\hline \multicolumn{17}{|l|}{ Cancún } \\
\hline Moda & 1 & 3 & 1 & 3 & 1 & 1 & 1 & 3 & 3 & 3 & 1 & 1 & 3 & 2 & 1 & 2 \\
\hline \multicolumn{17}{|l|}{ Chetumal } \\
\hline Media & 2.8 & 2.8 & 3.5 & 4.1 & 3.0 & 3.5 & 3.1 & 3.6 & 3.3 & 3.8 & 3.2 & 3.6 & 3.6 & 2.5 & 3.4 & 3.9 \\
\hline Moda & 2 & 3 & 5 & 3 & 2 & 4 & 3 & 4 & 4 & 5 & 2 & 3 & 3 & 1 & 2 & 3 \\
\hline \multicolumn{17}{|l|}{ Mérida } \\
\hline Media & 3.3 & 2.9 & 3.8 & 3.8 & 3.3 & 3.1 & 3.4 & 2.8 & 2.9 & 2.8 & 2.5 & 3.2 & 3.7 & 2.5 & 2.9 & 3.2 \\
\hline Moda & 4 & 1 & 4 & 4 & 3 & 3 & 5 & 4 & 2 & 3 & 1 & 3 & 5 & 1 & 1 & 4 \\
\hline Varianza & 2.1 & 2.9 & 1.2 & 1.6 & 2.3 & 2.3 & 2.6 & 1.5 & 2.1 & 1.4 & 1.8 & 1.6 & 2.7 & 1.7 & 2.8 & 2.7 \\
\hline \multicolumn{17}{|c|}{$\begin{array}{l}\text { Hablante B } \\
\text { (español como } \\
\text { distractor) }\end{array}$} \\
\hline \multicolumn{17}{|l|}{ Cancún } \\
\hline Media & 2.0 & 2.0 & 2.5 & 3.2 & 2.2 & 2.6 & 2.3 & 2.6 & 2.1 & 2.6 & 2.0 & 2.2 & 3.1 & 2.4 & 2.9 & 2.7 \\
\hline Moda & 1 & 1 & 2 & 3 & 1 & 3 & 2 & 2 & 1 & 2 & 1 & 2 & 3 & 2 & 1 & 3 \\
\hline Media & 2.8 & 3.0 & 3.5 & 3.9 & 3.2 & 3.2 & 3.6 & 3.5 & 3.5 & 3.6 & 3.1 & 3.6 & 3.5 & 3.0 & 4.0 & 4.2 \\
\hline Moda & 2 & 3 & 4 & 3 & 2 & 2 & 4 & 5 & 4 & 3 & 1 & 4 & 2 & 1 & 5 & 4 \\
\hline \multicolumn{17}{|l|}{ Mérida } \\
\hline Media & 2.9 & 2.7 & 2.4 & 3.0 & 2.5 & 2.9 & 2.5 & 3.0 & 2.3 & 3.0 & 2.7 & 2.9 & 3.4 & 2.6 & 3.2 & 3.3 \\
\hline Moda & 2 & 2 & 3 & 3 & 2 & 3 & 2 & 2 & 2 & 3 & 3 & 3 & 3 & 3 & 3 & 4 \\
\hline \multicolumn{17}{|c|}{$\begin{array}{l}\text { Hablante C } \\
\text { (inglés del trío } \\
\text { oculto) }\end{array}$} \\
\hline \multicolumn{17}{|l|}{ Cancún } \\
\hline Media & 2.0 & 2.0 & 2.0 & 3.4 & 2.4 & 2.8 & 1.8 & 2.3 & 2.0 & 2.3 & 2.2 & 2.5 & 3.3 & 2.0 & 3.4 & 2.7 \\
\hline Moda & 1 & 1 & 1 & 3 & 1 & 4 & 1 & 2 & 2 & 1 & 3 & 2 & 4 & 1 & 3 & 2 \\
\hline Varianza & 1.1 & .84 & 1.2 & 1.2 & 1.6 & 1.5 & .8 & 1.1 & .7 & 1.8 & .9 & 1.5 & 2.4 & 1.1 & 3.0 & 1.4 \\
\hline \multicolumn{17}{|l|}{ Chetumal } \\
\hline Media & 2.8 & 3.0 & 2.6 & 3.2 & 3.4 & 3.6 & 2.5 & 2.8 & 3.0 & 3.2 & 3.4 & 3.3 & 3.4 & 3.2 & 3.2 & 4.1 \\
\hline Moda & 2 & 3 & 2 & 3 & 3 & 5 & 2 & 4 & 4 & 3 & 5 & 2 & 3 & 3 & 2 & 4 \\
\hline
\end{tabular}




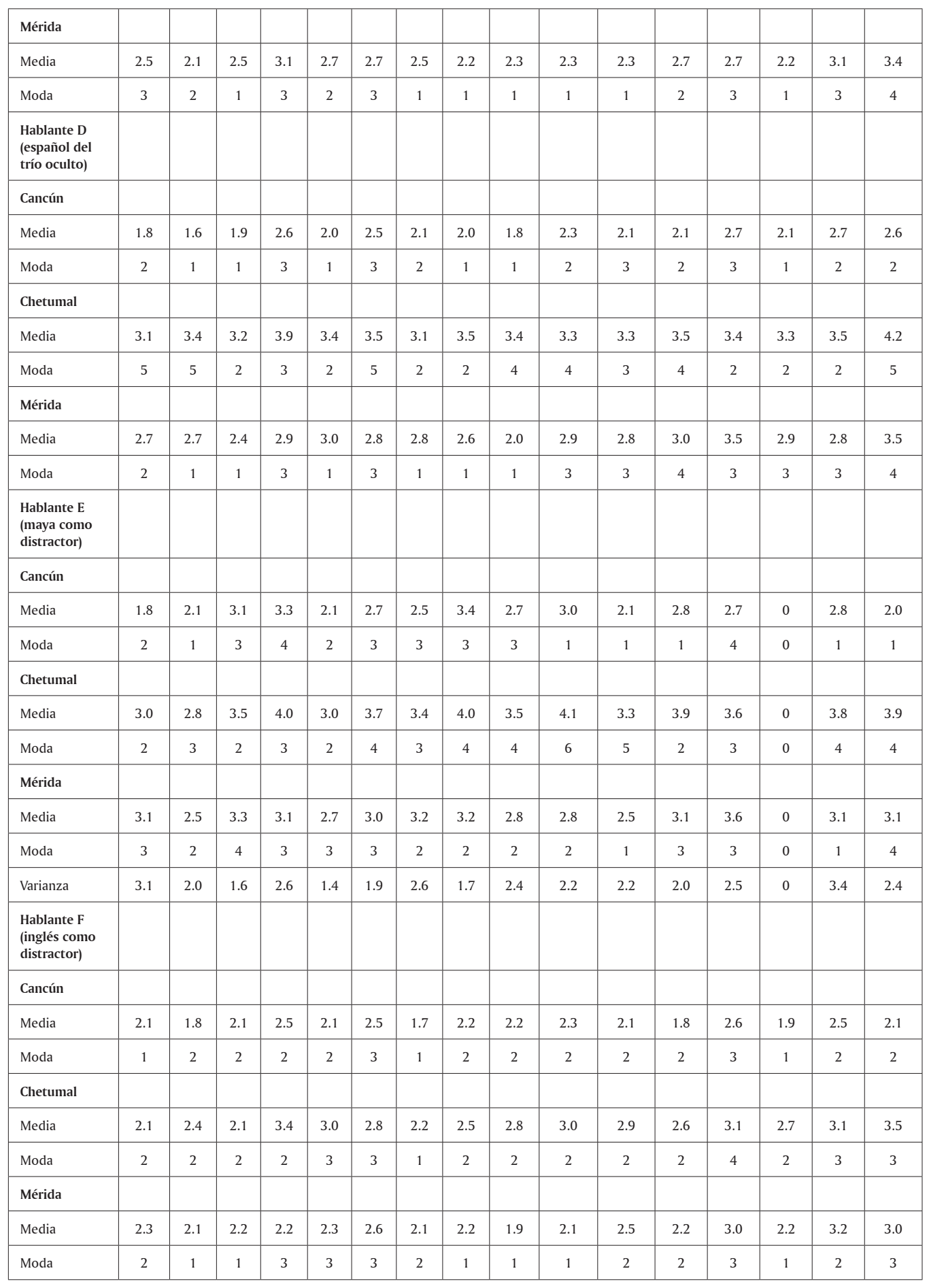

